Research Article

\title{
OPTIMIZATION OF PROCESS CONDITIONS FOR ADSORPTION OF METHYLENE BLUE ON FORMALDEHYDE-MODIFIED PEANUT SHELLS USING BOX-BEHNKEN EXPERIMENTAL DESIGN AND RESPONSE SURFACE METHODOLOGY
}

\begin{abstract}
Sinan KUTLUAY ${ }^{1^{*}}$, Orhan BAYTAR ${ }^{2}$, Ömer ŞAHİ ${ }^{3}$, Ali ARRAN ${ }^{4}$
This paper presents the use of formaldehyde-modified peanut shells as bioadsorbent for the adsorption of methylene blue for the first time. Firstly, the effect of medium $\mathrm{pH}$, which is one of the important parameters for the adsorption process, was determined. Then, the adsorption process conditions such as adsorption time (30-150 min), initial concentration (50-200 ppm) and ambient temperature $\left(25-40^{\circ} \mathrm{C}\right)$ were optimized by using response surface methodology (RSM) based on Box-Behnken experimental design. The pseudofirst-order and pseudo-second-order kinetic models were used to evaluate the adsorption kinetic in this study under optimized process conditions. The maximum adsorption capacity was found under optimum process conditions; 92.25 min adsorption time, $191.87 \mathrm{ppm}$ initial concentration, $39.70^{\circ} \mathrm{C}$ adsorption temperature. The maximum adsorption capacity for methylene blue was determined to be $43.84 \mathrm{mg} / \mathrm{g}$ using RSM based on Box-Behnken experimental design. Adsorption kinetic results showed that the plots of the pseudo-second-order kinetic model were fit the experimental data better when compared to the pseudo-first-order model. Besides, results indicated that formaldehyde-modified peanut shells could be used as low-cost and effective bioadsorbent for the adsorption of methylene blue, which is one of the important dyes. Furthermore, it was concluded that the RSM based on BoxBehnken experimental design can be applied successfully for the methylene adsorption process.
\end{abstract}

Keywords: Response surface methodology; Box-Behnken experimental design; Bioadsorbent; Methylene blue adsorption

\section{Introduction}

Increasing environmental pollution in the world is of great concern and has caused irreversible damages to all creatures. Industrial and domestic wastes are the main sources of organic, inorganic and biological pollutants in terrestrial ecosystems and waters. Wastes from the textile, paint, pesticide,

\footnotetext{
${ }^{1}$ Department of Chemical Engineering, University of Siirt, Siirt, Turkey, (sinankutluay@siirt.edu.tr, 04842121111) https://orcid.org/0000-0001-9493-918X

${ }^{2}$ Department of Chemical Engineering, University of Siirt, Siirt, Turkey, (baytarorhan@gmail.com, 04842121111) https://orcid.org/0000-0002-2915-202X

${ }^{3}$ Department of Chemical Engineering, University of Siirt, Siirt, Turkey, (sahinomer2002@yahoo.com, 04842121111) https://orcid.org/0000-0003-4575-3762

${ }^{4}$ Department of Chemical Engineering, University of Siirt, Siirt, Turkey, (ali.alaran2@ gmail.com, 04842121111) https://orcid.org//0000-0005-8659-215X
} 
fertilizer, pharmaceutical, refinery, leather and paper industries contain toxic and hazardous chemicals that pose a potential health hazard to life [1-3]. Dyes are widely used in many industries such as the textile, food and photoelectrochemical industries. Most dyes are dangerous and toxic, prevent water from penetrating sunlight and produce carcinogenic, teratogenic and mutagenic effects $[4,5]$. The intensive use of organic dyes causes them to be present in a high proportion of wastes and therefore solutions are recommended for their removal and disposal. Numerous studies have been conducted to remove micro-pollutants and water-soluble dyes from wastewater, including ultrafiltration, reverse osmosis, centrifugation, coagulation, oxidation, electrochemical methods, bio-healing, photocatalytic degradation and adsorption [6-10]. Among these methods, adsorption has been an economically viable approach that can remove multiple contaminants at the same time using a wide variety of adsorbents. Besides, adsorption technology has been recognized as an effective and economic control strategy as it has the potential to recover and reuse both adsorbent and adsorbent [11, 12]. Another approach to the problem of dyes adsorption is based on the use of materials in the natural environment known as bioadsorbents [13]. The reason for the use of activated carbon as an adsorbent in adsorption processes is due to its excellent properties $[14,15]$. However, since activated carbon is highly costly, it has encouraged researchers to synthesize other low-cost adsorbents to remove dyes. Therefore, yellow passionflower fruit waste [16], sugar cane [17], neem leaf powder (Azadirachta indica) [18], Posidonia Oceanica (L.) fibers [19], rice husk [20], wheat husk [21], garlic husk [22], coffee husks [23], papaya seeds [24], Brazilian pine-fruit shell [25], Elaeagnus Angustifolia seeds [26], onion skins [27] and acorn shell [28] to be included some biomasses were converted to cheap biosorbents.

The experimental design is applied for statistical modeling and systematic analysis of a problem in which the desired responses or output criteria are optimized by input variables or factors. One of the numerous experimental designs for empirical modeling is the response surface methodology (RSM), which can be considered a decisive sequential technique for developing leading processes, improving the design and formulation of new products and improving their performance. The greatest advantage of RSM over the traditional time-domain approach of a variable in each trial is the reduction in the number of experimental studies required for faster and more systematic investigation of process variables for selected-response parameters, including simultaneous and interaction of variables. One of the major advantages of RSM is that it allows the optimization of multiple experimental parameters that have an impact on the process response by performing a small number of experimental studies. The Box-Behnken design is the most commonly used combination design of the RSM model, which is adopted as an experimental design model to investigate the effect of the interaction of various parameter combinations [29-33]. The experimental design of Box-Behnken is an ideal method for performing a series of evaluations through rationalized design points along with a reliable curvature prediction [34].

In this study, RSM based on Box-Behnken experimental design was applied to optimize the process parameters that effective in adsorption of methylene blue, one of the most important dyes. This study aimed to investigate the use of formaldehyde-modified peanut shells as a low-cost bioadsorbent and to determine optimum process parameters for methylene blue adsorption. Also, it was aimed to develop an approach that provides a better understanding of the effects of conditions such as adsorption time, methylene blue initial concentration and adsorption temperature on the adsorption capacity and to determine the maximum adsorption capacity under optimum conditions. 


\section{Materials and methods}

\subsection{Preparation of bioadsorbent}

In this study, the adsorption of methylene blue used in the paint and pharmaceutical industry using peanut shells was investigated. At the beginning of the study, peanut shells were ground (Retsch SR300) and classified according to particle size (Retsch AS200). Peanut shells were treated for 24 hours with $1 \%$ formaldehyde solution in $1 / 5$ ratio (peanut shells: formaldehyde; w/v) for color immobilization and removal of water-soluble substances. The peanut shells were then removed by filtration and washed with hot deionized water to remove formaldehyde. The washed peanut shells were dried at $80^{\circ} \mathrm{C}$ for 24 hours and stored in closed containers for use in adsorption experiments.

\subsection{Adsorption experiments}

In adsorption experiments, the effects of parameters such as solution $\mathrm{pH}(2,4,6,8$ and 10), adsorption time (30-150 min), methylene blue initial concentration $(50-200 \mathrm{ppm})$ and ambient temperature $\left(25-40^{\circ} \mathrm{C}\right)$ were determined separately. The studies were started by examining the effect of solution $\mathrm{pH}$ and $\mathrm{pH}$ adjustments were performed using $0.1 \mathrm{M} \mathrm{NaOH}$ and $0.1 \mathrm{M} \mathrm{HCl}$. At the end of the process, solution concentrations were determined by a UV-Vis spectrophotometer (Hitachi U-0080D) at a wavenumber of $616 \mathrm{~nm}$.

The adsorption capacity of methylene blue on the formaldehyde-modified peanut shells was calculated with equation 1 .

$$
q=\frac{C_{0}-C_{e}}{m} \times V
$$

Where $\mathrm{q}(\mathrm{mg} / \mathrm{g})$ is the adsorption capacity, $\mathrm{V}(\mathrm{L})$ is the solution volume, $\mathrm{m}(\mathrm{g})$ is the amount of adsorbent and $\mathrm{C}_{0}(\mathrm{ppm})$ and $\mathrm{C}_{\mathrm{e}}(\mathrm{ppm})$ are the initial and equilibrium concentrations of methylene blue.

\subsection{Design of experiments}

In the experimental design, the relationship between adsorption time $\left(\mathrm{X}_{1}\right)$, initial concentration $\left(\mathrm{X}_{2}\right)$ and temperature $\left(\mathrm{X}_{3}\right)$ independent variables and adsorption capacity $(\mathrm{Y})$ response was modeled by using Box-Behnken approach and RSM. The values of the independent variables for design points are presented in Table 1. The relationship of the response variable with the independent variables was represented by the second-order polynomial equation given below. The statistical significance level of the model was measured with the F-value $(\mathrm{p}<0.05)$ at $95 \%$ confidence interval. Adeq precision, regression coefficient $\left(R^{2}\right.$ ), adjusted regression coefficient (Adj. $R^{2}$ ) and predicted regression coefficient (Pred. $\mathrm{R}^{2}$ ) parameters were used in the evaluation of the model.

Table 1. Independent variables and levels of the process for Box-Behnken experimental design

\begin{tabular}{lcccc}
\hline \multirow{2}{*}{ Independent variables } & \multirow{2}{*}{ Seymbol } & \multicolumn{3}{c}{ Levels of independent variables } \\
\cline { 2 - 4 } & & -1 & 0 & +1 \\
\hline Adsorption time $(\mathrm{min})$ & $\mathrm{X}_{1}$ & 30 & 90 & 150 \\
Initial concentration $(\mathrm{ppm})$ & $\mathrm{X}_{2}$ & 50 & 125 & 200 \\
Temperature $\left({ }^{\circ} \mathrm{C}\right)$ & $\mathrm{X}_{3}$ & 25 & 32.5 & 40 \\
\hline
\end{tabular}

In the optimization process, the response can be correlated with variables selected by linear or quadratic models. A quadratic model was given in the following equation.

$$
\begin{gathered}
Y=b_{0}+b_{1} X_{1}+b_{2} X_{2}+b_{3} X_{3}+b_{12} X_{1} X_{2}+b_{13} X_{1} X_{3}+b_{23} X_{2} X_{3} \\
+b_{11} X_{1}^{2}+b_{22} X_{2}^{2}+b_{33} X_{3}^{2}
\end{gathered}
$$


Where $\mathrm{Y}$ is the response variable $(\mathrm{q}), \mathrm{b}_{0}$ is constant, $\mathrm{b}_{\mathrm{i}}$ is linear coefficient, $\mathrm{b}_{\mathrm{ii}}$ is quadratic coefficient, $b_{i j}$ is interaction coefficient, $X_{i}$ is the coded variable level and $i$ or $j$ are the number of independent variables.

\subsection{Analysis of variance (ANOVA)}

The results obtained by Box-Behnken experimental design studies are given in the statistical analysis program. The results of the studies using the experimental data are evaluated according to statistical data such as p-value calculated by the program, adequate precision, adjusted and predicted regression coefficients (Adj. $\mathrm{R}^{2}$, Pred. $\mathrm{R}^{2}$ ). From the data obtained statistically, it was paid attention that the p-value is less than 0.05 . Because the p-value is less than 0.05 , the effect of the variable on the response is statistically significant, if it is greater than 0.100 indicates that the effect of the variables on the response is statistically insignificant. Besides, a sufficient sensitivity value greater than 4 indicates that the model used can be included in the design area. The difference between the adjusted regression coefficient and predicted regression coefficient values is less than 0.2 is another criterion showing the suitability of the model.

\section{Results and discussion}

\section{1. $\mathrm{pH}$ effect on the adsorption process}

Studies examining the effect of solution $\mathrm{pH}$ on methylene blue adsorption capacity were performed for $100 \mathrm{ppm}$ initial concentration and $30^{\circ} \mathrm{C}$ process temperature, 24 hours impregnation time and 75 rpm stirring speed. The results were given in Figure 1.

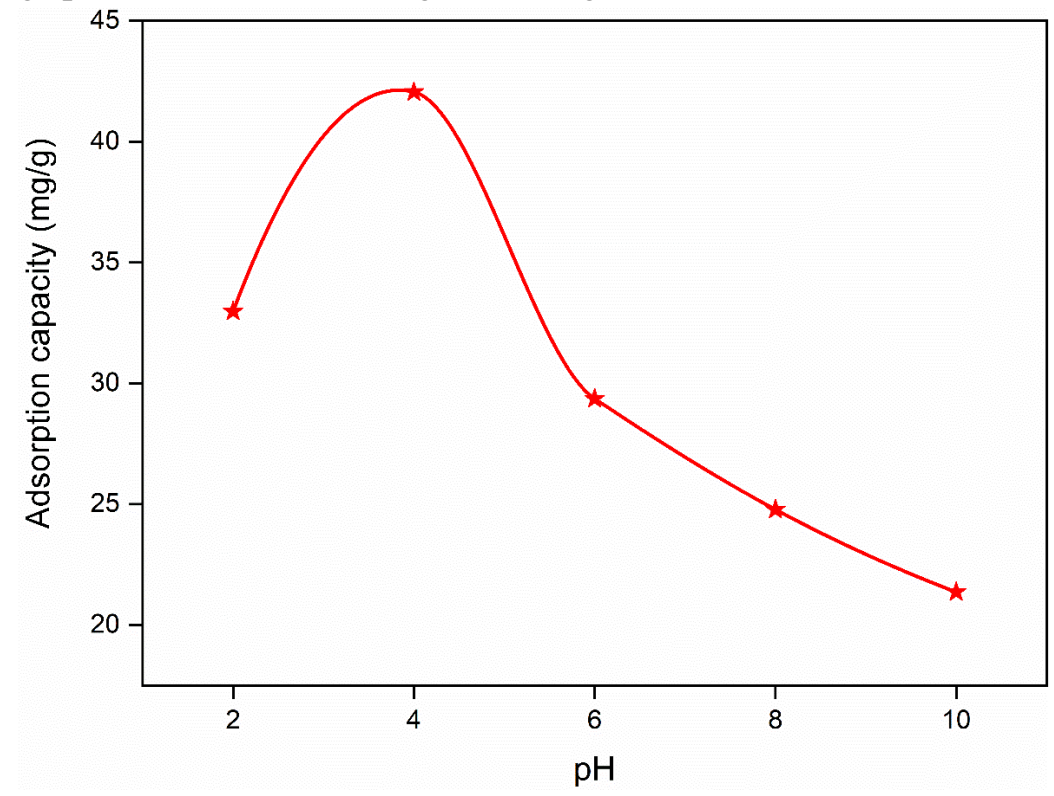

Figure 1. pH effect on the adsorption capacity of methylene blue.

As can be seen from the figure, especially after $\mathrm{pH}=4$, the adsorption capacity decreased with increasing solution $\mathrm{pH}$. This is probably due to the excess $\mathrm{OH}^{-}$ion in the medium and the cationic structure of the dye. At basic pHs, it is thought that excess $\mathrm{OH}^{-}$ion in the environment forms complex with cationic dye and reduces adsorption. It was also seen that adsorption capacity decreased because the $\mathrm{pH}$ is less than 4 . The possible reason for this is thought to be the repulsion of the cationic dyes as a 
result of the decrease in the negative charge regions of the adsorbent when the $\mathrm{pH}$ decreases and the increase in the positive charge regions on the surface.

\subsection{Statistical analysis and modeling by RSM}

The adsorption capacity response variable value obtained from the experiments carried out according to the experimental design created with Box-Behnken approach-based RSM are presented in Table 2 .

Table 2. Experimental design and results of the Box-Behnken experimental design.

\begin{tabular}{ccccc}
\hline & Factor $\mathbf{1}$ & Factor $\mathbf{1}$ & Factor $\mathbf{1}$ & Response \\
\hline Run & $\mathbf{X}_{\mathbf{1}}$ : Time $(\mathbf{m i n})$ & $\mathbf{X}_{\mathbf{2}}$ : Concentration $(\mathbf{p p m})$ & $\mathbf{X}_{\mathbf{3}}$ : Temperature $\left({ }^{\circ} \mathbf{C}\right)$ & Adsorption capacity $(\mathbf{m g} / \mathbf{g})$ \\
\hline 1 & 150 & 125 & 40 & 42.93 \\
2 & 150 & 125 & 25 & 25.20 \\
3 & 90 & 125 & 32.5 & 33.40 \\
4 & 90 & 125 & 32.5 & 35.87 \\
5 & 90 & 50 & 25 & 12.08 \\
6 & 90 & 125 & 32.5 & 36.36 \\
7 & 150 & 125 & 32.5 & 25.39 \\
8 & 30 & 50 & 25 & 14.89 \\
9 & 90 & 125 & 40 & 21.32 \\
10 & 30 & 200 & 40 & 33.58 \\
11 & 150 & 50 & 32.5 & 39.92 \\
12 & 30 & 200 & 32.5 & 12.38 \\
13 & 30 & 200 & 32.5 & 26.21 \\
14 & 90 & 200 & 40 & 42.79 \\
15 & 90 & & 25 & 23.27 \\
\hline
\end{tabular}

Table 3. Model summary statistics for methylene blue adsorption response.

\begin{tabular}{lcccccc}
\hline Source & $\mathbf{R}^{\mathbf{2}}$ & Adjusted $^{\mathbf{2}}$ & Predicted R $^{\mathbf{2}}$ & F-value & p-value & \\
\hline Linear & 0.8282 & 0.7813 & 0.7265 & 17.68 & 0.0002 & \\
2FI & 0.8457 & 0.7300 & 0.5753 & 0.3026 & 0.8229 & \\
Quadratic & 0.9863 & 0.9616 & 0.8259 & 17.11 & 0.0046 & Suggested \\
Cubic & 0.9967 & 0.9770 & & 2.12 & 0.3367 & \\
\hline
\end{tabular}

Some statistical results were evaluated, such as ANOVA to check the accuracy of the model for methylene blue adsorption. It was suggested that adsorption capacity was a model that fitted the quadratic equation according to ANOVA results (Table 3). According to ANOVA results, the quadratic equation obtained for methylene blue adsorption was given below.

$$
\begin{gathered}
q=40.15+2.22 X_{1}+7.16 X_{2}+8.34 X_{3}+3.63 X_{1}+1.67 X_{1} X_{3} \\
+2.20 X_{2} X_{3}-4.63 X_{1}^{2}-0.98 X_{2}^{2}-3.36 X_{3}^{2}
\end{gathered}
$$

In the equation, $q$ was represented the adsorption capacity of methylene blue, and $\mathrm{X}_{1}, \mathrm{X}_{2}$, and $\mathrm{X}_{3}$ were independent variables, as previously mentioned. To demonstrate the validity of this model, qexp. and $\mathrm{q}_{\text {mod. }}(\mathrm{mg} / \mathrm{g})$ were compared to the adsorption capacities determined by experimental and model (Figure 2). As can be seen from Figure 2, the estimated results with the quadratic regression model and the actual experimental results were found to be quite close to each other. In addition, the magnitude of the independent variable $\left(\mathrm{X}_{1}, \mathrm{X}_{2}\right.$, and $\left.\mathrm{X}_{3}\right)$ coefficients in the model equations confirmed the ANOVA results according to the most effective parameter evaluation. 


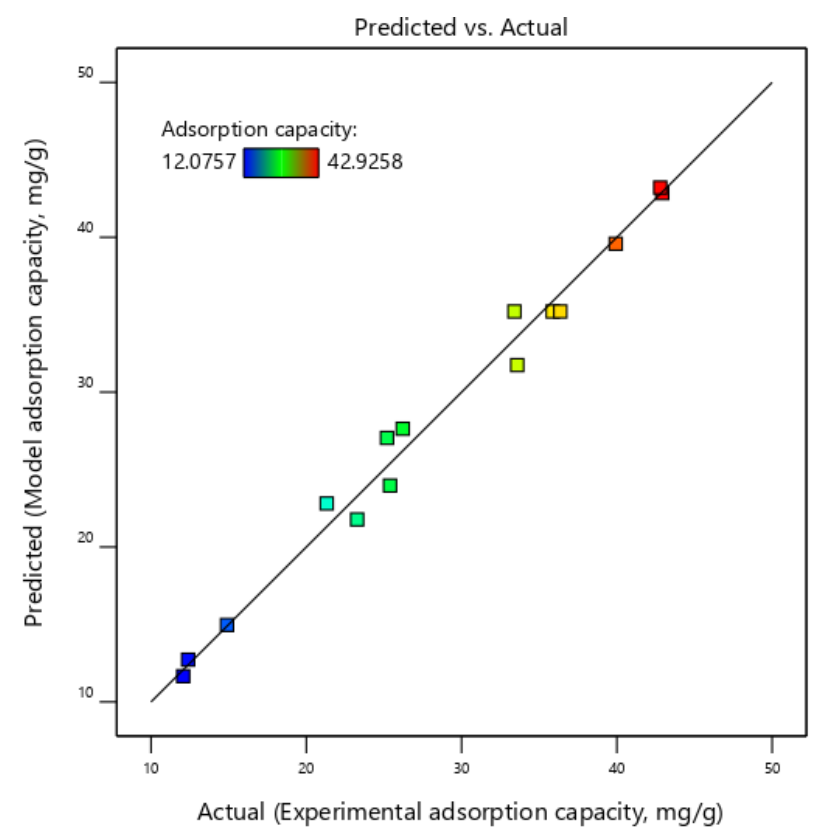

Figure 2. Comparison of experimental and model adsorption capacities of methylene blue.

Table 4. ANOVA for the quadratic model.

\begin{tabular}{lcccccc}
\hline Source & $\begin{array}{c}\text { Sum of } \\
\text { Squares }\end{array}$ & $\begin{array}{c}\text { Degree of } \\
\text { Freedom }\end{array}$ & Mean Square & F-value & p-value & \\
\hline Model & 1506.98 & 9 & 167.44 & 40.00 & 0.0004 & significant \\
$\mathrm{X}_{1}$-Time & 268.69 & 1 & 268.69 & 64.18 & 0.0005 & \\
$\mathrm{X}_{2}$-Concentration & 465.72 & 1 & 465.72 & 111.25 & 0.0001 & \\
$\mathrm{X}_{3}$-Temperature & 531.01 & 1 & 531.01 & 126.84 & $<0.0001$ & \\
$\mathrm{X}_{1} \mathrm{X}_{2}$ & 0.1268 & 1 & 0.1268 & 0.0303 & 0.8686 & \\
$\mathrm{X}_{1} \mathrm{X}_{3}$ & 0.2348 & 1 & 0.2348 & 0.0561 & 0.8222 & \\
$\mathrm{X}_{2} \mathrm{X}_{3}$ & 26.39 & 1 & 26.39 & 6.30 & 0.0538 & \\
$\mathrm{X}_{1}{ }^{2}$ & 22.58 & 1 & 22.58 & 5.39 & 0.0678 & \\
$\mathrm{X}_{2}{ }^{2}$ & 168.67 & 1 & 168.67 & 40.29 & 0.0014 & \\
$\mathrm{X}_{3}{ }^{2}$ & 47.49 & 1 & 47.49 & 11.34 & 0.0199 & \\
Residual $_{\text {Lack of Fit }}^{20.93}$ & 5 & 4.19 & & & \\
Pure Error & 15.92 & 3 & 5.31 & & & \\
Cor Total & 5.01 & 2 & 2.51 & & & \\
\hline
\end{tabular}

ANOVA results of the quadratic polynomial function proposed by Box-Behnken approach for the relationship between the response variable and independent variables are given in Table 4. Accordingly, the F-value of the model determined by the adsorption capacity ANOVA results of methylene blue was found to be significant at 40.00 . Adeq precision value measures the signal to noise ratio. This ratio is requested to be greater than 4.00 in respect of the model's estimation suitability. Accordingly, as shown in Table 4, the adeq precision of the model for methylene blue was determined to be 18.89 , which means that the model is suitable for these studies. Besides, the p-value of the model is less than 0.05, meaning that the terms of the model are meaningful and that it is more than 0.100 means that it is meaningless. According to the model obtained from the methylene blue study, p-values less than 0.05 showed that the model terms were significant. Adj. $\mathrm{R}^{2}$ and Pred. $\mathrm{R}^{2}$ are expected to be close to each other and the difference between them is expected to be less than $0.2[35,36]$. The Pred. $\mathrm{R}^{2}$ of 0.8259 is in reasonable agreement with the Adj. $\mathrm{R}^{2}$ of 0.9616 ; i.e. the difference is less than 0.2 for the methylene blue adsorption capacity response. This result showed that the model has high precision and reliability. 


\subsection{The effect of adsorption time and initial concentration on the adsorption capacity}

The results obtained for the studies in which the effect of adsorption time and initial solution concentration on the methylene blue adsorption capacity are examined are given in Figure 2. As can be seen from the figure, the adsorption capacity increased with increasing adsorption time and initial concentration. This result showed that the adsorption of methylene blue depends on time and initial concentration. When this result and ANOVA results (F-value and p-value) were evaluated together, it was concluded that initial concentration was more effective than adsorption time.
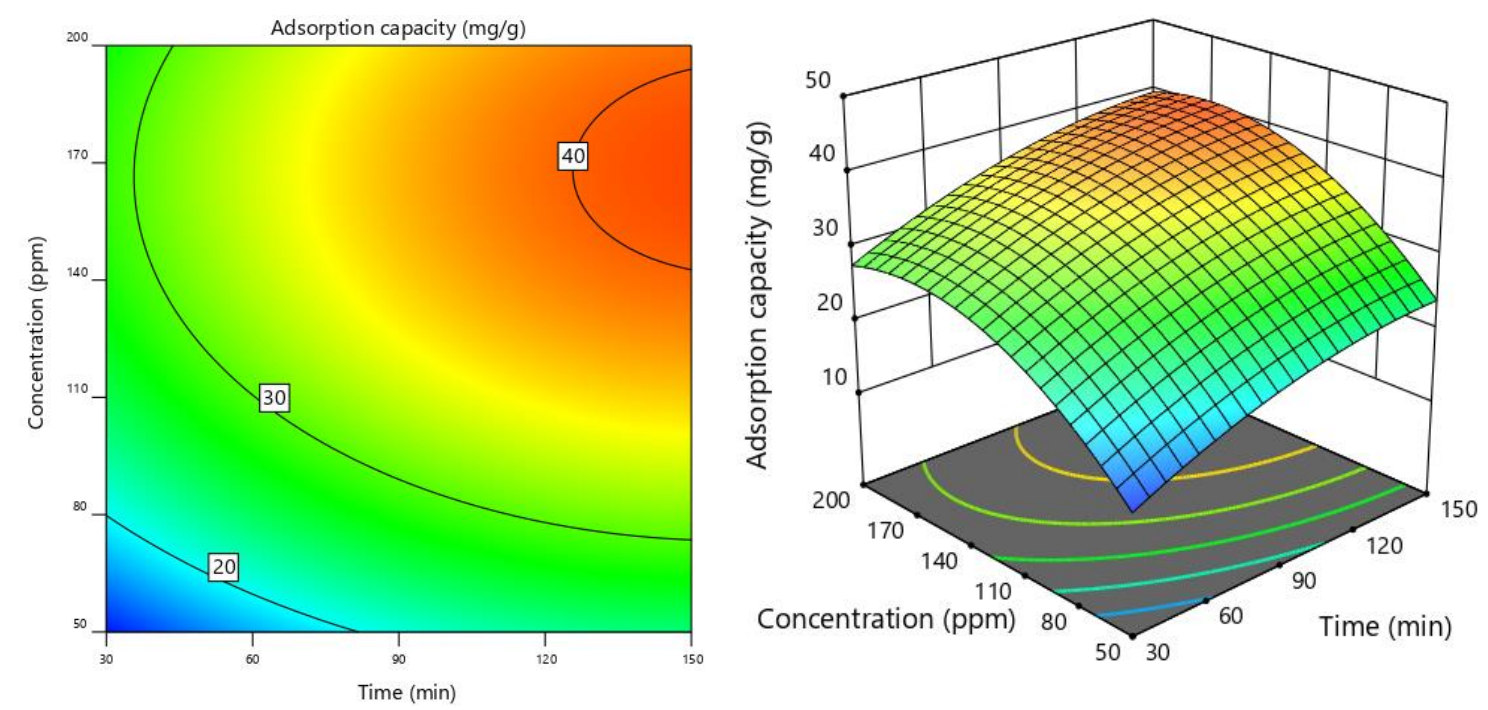

Figure 3. Contour and 3D response surface graphs showing the effect of time and methylene blue initial concentration on the adsorption capacity (Process conditions: $\mathrm{pH}=4$, temperature $=32.5^{\circ} \mathrm{C}$, amount of adsorbent $=0.1 \mathrm{~g}$, stirring speed $=75 \mathrm{rpm})$.

\subsection{The effect of adsorption time and temperature on the adsorption capacity}

The results obtained for the studies in which the effect of adsorption time and solution temperature on methylene blue adsorption capacity are examined are given in Figure 3. As can be seen from the figure, the amount of methylene blue adsorbed generally tends to increase with increasing adsorption time and temperature. This result showed that the adsorption capacity of methylene blue depends on both time and temperature. Based on ANOVA results (F-value and p-value), it was found that this result was significant and the effect of temperature parameter on the adsorption process was higher. 

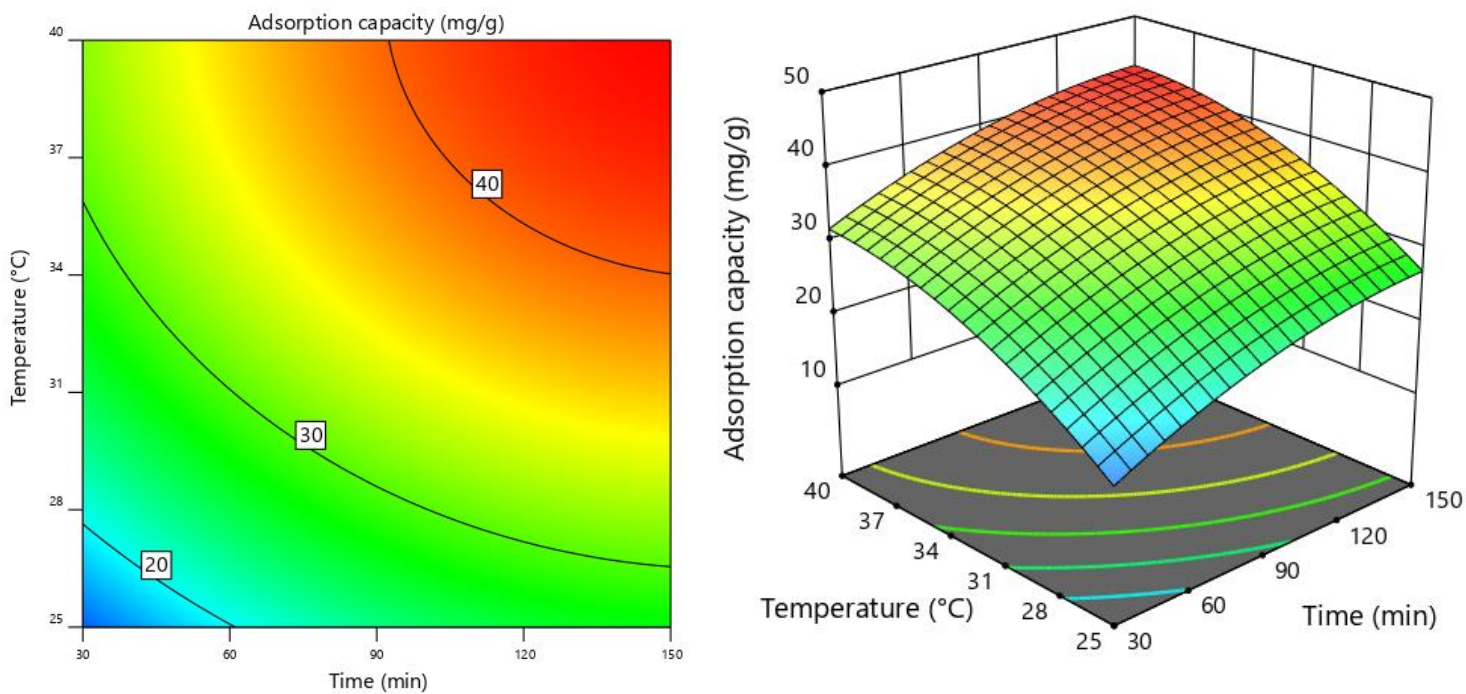

Figure 4. Contour and 3D response surface graphs showing the effect of time and temperature on the adsorption capacity (Process conditions: $\mathrm{pH}=4$, initial concentration $=125 \mathrm{ppm}$, amount of adsorbent $=0.1 \mathrm{~g} / 100 \mathrm{~mL}$, stirring speed $=75 \mathrm{rpm})$.

\subsection{The effect of initial concentration and temperature on the adsorption capacity}

The results obtained for the studies examining the effect of solution initial concentration and temperature on methylene blue adsorption capacity are given in Figure 4. As can be seen from the figure, the adsorption capacity generally tends to increase with increasing temperature and initial concentration. This result showed that adsorption capacity was dependent on both initial concentration and temperature. It can be said that the temperature is more effective on the methylene blue adsorption capacity according to the evaluation made based on ANOVA results (F-value and p-value) in which binary parameter effects are determined.
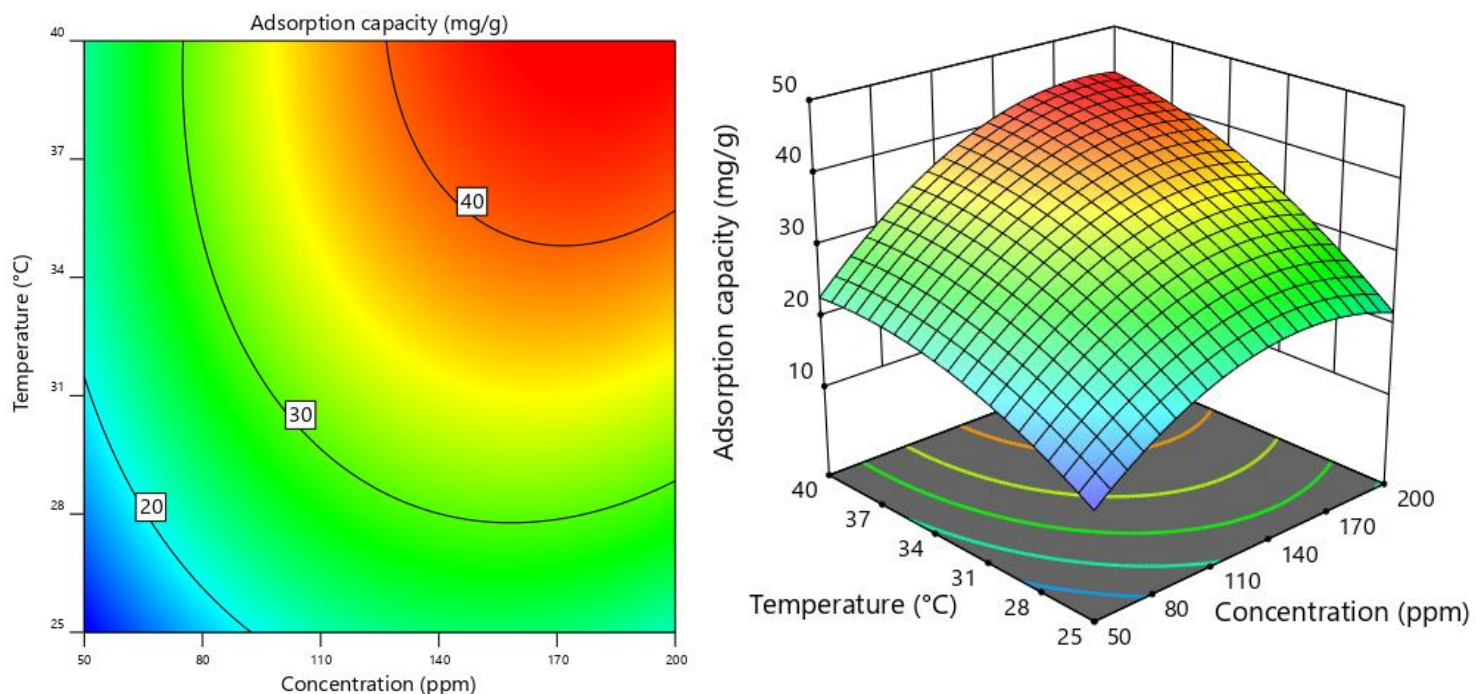

Figure 5. Contour and 3D response surface graphs showing the effect of initial concentration and temperature on the adsorption capacity (Process conditions: $\mathrm{pH}=4$, adsorption time $=90 \mathrm{~min}$, amount of adsorbent $=0.1 \mathrm{~g} / 100 \mathrm{~mL}$, stirring speed $=75 \mathrm{rpm}$ ). 


\subsection{Optimization of process parameters for methylene blue adsorption}

The main objective of this study was to find a combination of experimental variable levels that provide the maximum adsorption capacity value for the methylene blue response variable. Adsorption time $\left(\mathrm{A}: \mathrm{X}_{1}\right)$, initial concentration $\left(\mathrm{B}: \mathrm{X}_{2}\right)$ and $\left(\mathrm{C}: \mathrm{X}_{3}\right)$ temperature variables were optimized to determine the maximum adsorption capacity in the studied range. In this context, in the adsorption study using modified peanut shells, the optimum numerical values of experimental parameters were determined by applying the Box-Behnken experimental design method as an effective tool to find the maximum adsorption capacity of methylene blue (Figure 6). Under the determined optimum conditions, the maximum adsorption capacity of methylene blue was found as $43.84 \mathrm{mg} / \mathrm{g}$. The desirability [37] of these parameters, which completely represents the desired or ideal response values, was found to be 0.999 for methylene blue adsorption. For optimum point evaluation, validation experiments were performed for optimum process conditions corresponding to 10 different desirability levels among different desirability levels recommended by the package program and under these conditions, the maximum adsorption capacity for methylene blue was obtained as $42.95 \mathrm{mg} / \mathrm{g}$. According to the results of the validation tests, the absolute error values between the test results obtained for the methylene blue response and the proposition values are below $3 \%$ and are acceptable. Based on all these evaluations, it can be concluded that the proposed model outputs are fully consistent with the experimental results.
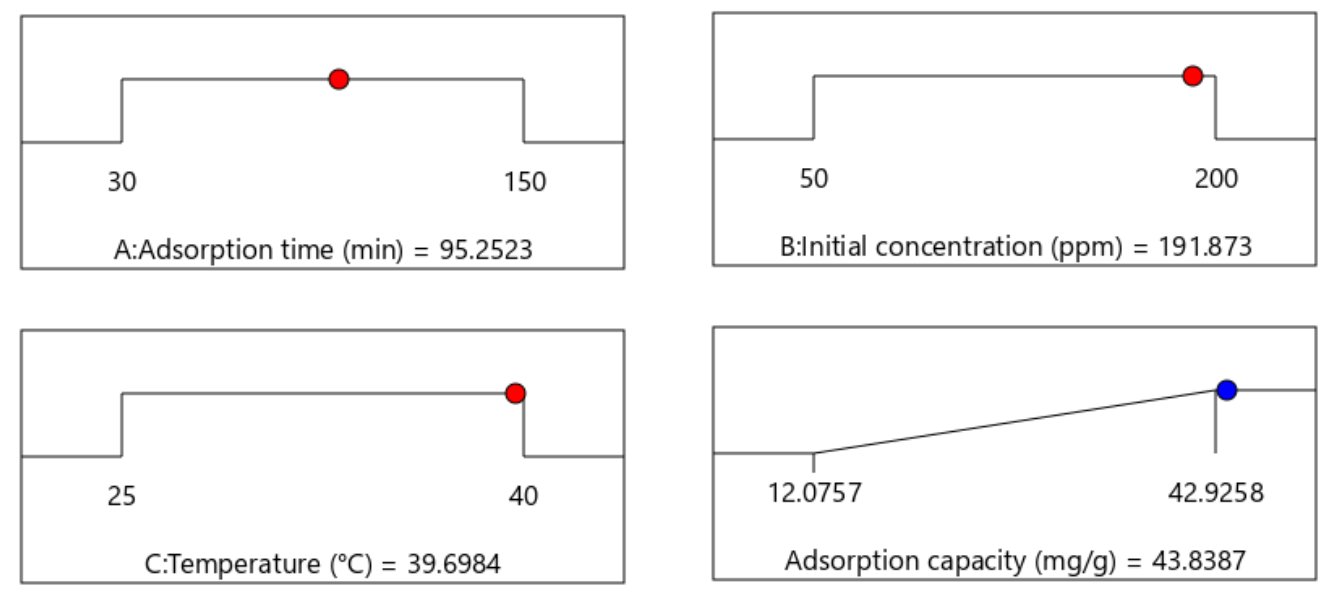

Figure 6. Desirability ramp for numerical optimization of adsorption conditions.

\subsection{Adsorption kinetic studies}

Adsorption kinetics is an important characteristic that must be examined to understand the adsorption dynamics between adsorbate and adsorbent and to determine the kinetic parameters [38]. The pseudo-first-order and pseudo-second-order kinetic models were used to evaluate the adsorption kinetic in this study under optimized process conditions. The validity of kinetic models was assessed by $R^{2}$, regression coefficient, and $\Delta q(\%)$. The non-linear forms and parameters of the kinetic models studied are given in Table 5. Adsorption kinetic models were fitted to experimental data using non-linear regression analysis. The estimated kinetic parameters were listed in Table 6. The non-linear plots of the pseudo-first-order and pseudo-second-order kinetic models are shown in Figure 7. As can be seen from this Figure, it is clear that the plots of the pseudo-second-order kinetic model were fit the experimental data better when compared to the pseudo-first-order model. 
Table 5. Non-linear forms and parameters of the adsorption kinetic models

\begin{tabular}{|c|c|c|}
\hline Kinetic models/Standard deviation & Equation & Reference \\
\hline Pseudo-first-order model & $q_{t}=q_{e}\left[1-e^{\left(-k_{1} t\right)}\right]^{1}$ & [39] \\
\hline Pseudo-second-order model & $q_{t}=\frac{k_{2} q_{e}^{2} t}{1+k_{2} q_{e} t}{ }^{2}$ & [40] \\
\hline Normalized standard deviation & $\Delta q(\%)=100 \sqrt{\frac{\sum\left[\left(q_{\text {exp. }}-q_{\text {mod. }}\right) / q_{\text {exp. }}\right]^{2}}{N-1}} 3$ & [41] \\
\hline
\end{tabular}

${ }^{1} \mathrm{q}_{\mathrm{e}}$ and $\mathrm{q}_{\mathrm{t}}(\mathrm{mg} / \mathrm{g})=$ the adsorption capacities at equilibrium and at time $\mathrm{t}(\mathrm{min})$, respectively, $\mathrm{k}_{1}=$ the adsorption rate constant of the pseudo-first-order kinetic model ( $1 / \mathrm{min})$.

${ }^{2} \mathrm{k}_{2}=$ the adsorption rate constant of the pseudo-second-order kinetic model $(\mathrm{g} / \mathrm{mg} / \mathrm{min})$.

${ }^{3} \mathrm{q}_{\text {exp. and }} \mathrm{q}_{\mathrm{mod} .}(\mathrm{mg} / \mathrm{g})=$ the adsorption capacities of kinetic experiments and models, respectively, $\mathrm{N}=$ the number of adsorption kinetics data points, $\Delta \mathrm{q}=$ the normalized standard deviation.

Table 6. Kinetic models parameters for the adsorption of methylene blue on formaldehyde-modified peanut shells

\begin{tabular}{llc}
\hline Kinetic models & Parameters & Results \\
\hline \multirow{3}{*}{ Pseudo-first-order } & $\mathrm{q}_{\mathrm{e}}(\mathrm{mg} / \mathrm{g})$ & 23.60 \\
& $\mathrm{k}_{1}(1 / \mathrm{min})$ & 0.029 \\
& $\mathrm{R}^{2}$ & 0.971 \\
& $\Delta \mathrm{q}(\%)$ & 9.65 \\
Pseudo-second-order & $\mathrm{q}_{\mathrm{e}}(\mathrm{mg} / \mathrm{g})$ & 27.07 \\
& $\mathrm{k}_{2}(\mathrm{~g} / \mathrm{mg} / \mathrm{min})$ & 0.00096 \\
& $\mathrm{R}^{2}$ & 0.997 \\
& $\Delta \mathrm{q}(\%)$ & 1.85 \\
\hline
\end{tabular}

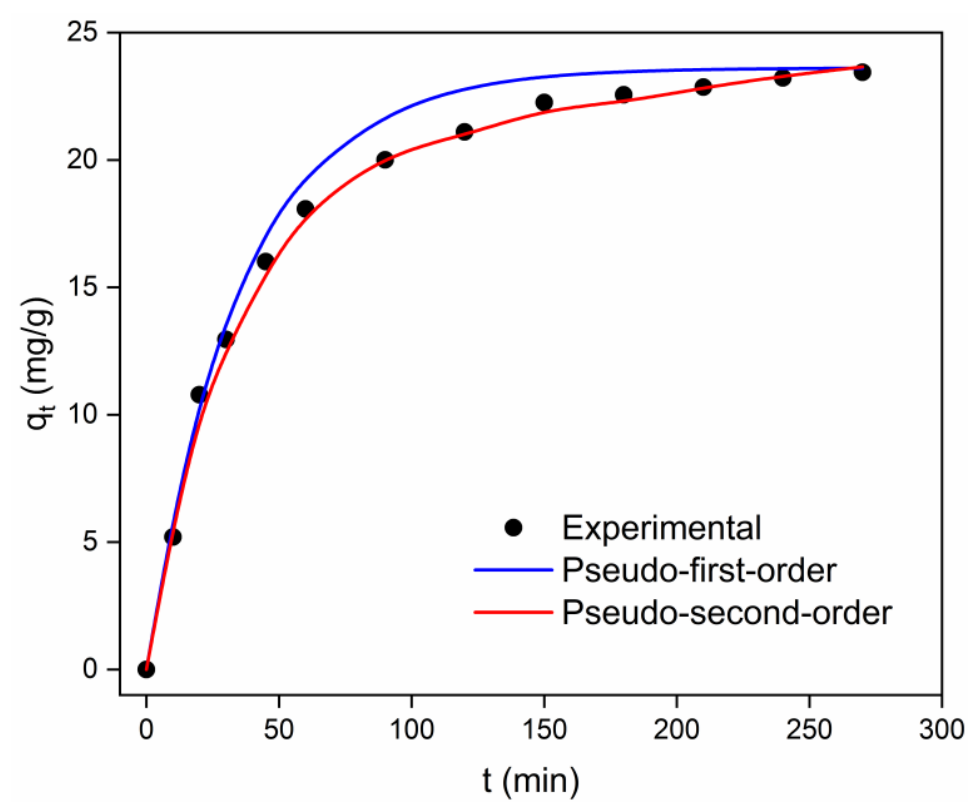

Figure 7. Adsorption kinetics model fitting results and experimental kinetics of methylene blue on the formaldehydemodified peanut shells.

\section{Conclusions}

In this study, the first use of formaldehyde-modified peanut shells as bioadsorbent to remove methylene blue from aqueous solutions was investigated. Firstly, the effect of solution $\mathrm{pH}$, which is one of the important parameters for the adsorption process, was determined. Then, conditions such as adsorption time, initial concentration and ambient temperature, which play a key role in the adsorption process, were optimized using the RSM based on Box-Behnken experimental design. The pseudo-firstorder and pseudo-second-order kinetic models were used to evaluate the adsorption kinetic in this study 
under optimized process conditions. Adsorption kinetic results showed that the plots of the pseudosecond-order kinetic model were fit the experimental data better when compared to the pseudo-firstorder model. Besides, the maximum adsorption capacity was found under optimum process conditions; $95.25 \mathrm{~min}$ adsorption time, $191.87 \mathrm{ppm}$ initial concentration, $39.70^{\circ} \mathrm{C}$ adsorption temperature. The maximum adsorption capacity for methylene blue was determined to be $43.84 \mathrm{mg} / \mathrm{g}$ using RSM based on Box-Behnken experimental design. Also, results indicated that formaldehyde-modified peanut shells could be used as low cost and effective bioadsorbent for the adsorption of methylene blue, which is one of the important dyes. Furthermore, it was concluded that the RSM based on Box-Behnken experimental design can be applied successfully for the methylene adsorption process.

\section{References}

[1] Richardson, S.D., Kimura, S.Y., Water Analysis: Emerging Contaminants and Current Issues, Analytical Chemistry, 88 (2016), pp.546-582.

[2] Schwarzenbach, R.P., Escher, B.I., Fenner, K., Hofstetter, T.B., Johnson, C.A., Von Gunten, U., Wehrli, B., The Challenge of Micropollutants in Aquatic Systems, Science, 313 (2006), pp.1072-1077.

[3] Shannon, M.A., Bohn, P.W., Elimelech, M., Georgiadis, J.G., Marinas, B.J., Mayes, A.M., Science and Technology for Water Purification in the Coming Decades, Nature, 452 (2008), pp.301-310.

[4] Birhanl1, A., Ozmen, M., Evaluation of the Toxicity and Teratogenity of Six Commercial Textile Dyes using the Frog Embryo Teratogenesis Assay-Xenopus, Drug and Chemical Toxicology, 28 (2005) 51-65.

[5] Jadhav, J., Kalyani, D., Telke, A., Phugare, S., Govindwar, S.P., Evaluation of the Efficacy of a Bacterial Consortium for the Removal of Color, Reduction of Heavy Metals, and Toxicity from Textile Dye Effluent, Bioresource Technology, 101 (2010), pp.165-173.

[6] Ali, I., New Generation Adsorbents for Water Treatment, Chemical Reviews, 112 (2012), pp.5073-5091.

[7] Brillas, E., Martínez-Huitle, C.A., Decontamination of Wastewaters Containing Synthetic Organic Dyes by Electrochemical Methods, an Updated Review, Applied Catalysis B: Environmental, 166 (2015), pp.603-643.

[8] Chong, M.N., Jin, B., Chow, C.W., Saint, C., Recent Developments in Photocatalytic Water Treatment Technology: A Review, Water research, 44 (2010), pp.2997-3027.

[9] Kumar, S.S., Shantkriti, S., Muruganandham, T., Murugesh, E., Rane, N., Govindwar, S.P., Bioinformatics Aided Microbial Approach for Bioremediation of Wastewater Containing Textile Dyes, Ecological Informatics, 31 (2016), pp.112-121.

[10] Li, J., Wang, X., Zhao, G., Chen, C., Chai, Z., Alsaedi, A., Hayat, T., Wang, X., Metal-Organic FrameworkBased Materials: Superior Adsorbents for the Capture of Toxic and Radioactive Metal Ions, Chemical Society Reviews, 47 (2018), pp.2322-2356.

[11] Kutluay, S., Baytar, O., Şahin Ö., Equilibrium, Kinetic and Thermodynamic Studies for Dynamic Adsorption of Benzene in Gas Phase onto Activated Carbon Produced from Elaeagnus Angustifolia Seeds, Journal of Environmental Chemical Engineering, 7 (2019), pp.102947.

[12] Kutluay, S., Baytar, O., Şahin Ö., Adsorption Kinetics, Equilibrium and Thermodynamics of Gas-Phase Toluene onto Char Produced from Almond Shells, Research on Engineering Structures and Materials, 5 (2019), pp.279-298.

[13] Khorramfar, S., Mahmoodi, N.M., Arami, M., Gharanjig, K., Equilibrium and Kinetic Studies of the Cationic Dye Removal Capability of a Novel Biosorbent Tamarindus Indica from Textile Wastewater, Coloration Technology, 126 (2010), pp.261-268.

[14] Baytar, O., Sahin, Ö., Saka, C., Sequential Application of Microwave and Conventional Heating Methods for Preparation of Activated Carbon from Biomass and Its Methylene Blue Adsorption, Applied Thermal Engineering, 138 (2018), pp.542-551.

[15] Özhan, A., Şahin, Ö., Küçük, M.M., Saka, C., Preparation and Characterization of Activated Carbon from Pine Cone by Microwave-Induced $\mathrm{ZnCl}_{2}$ Activation and Its Effects on the Adsorption of Methylene Blue, Cellulose, 21 (2014), pp.2457-2467.

[16] Pavan, F.A., Lima, E.C., Dias, S.L., Mazzocato, A.C., Methylene Blue Biosorption from Aqueous Solutions by Yellow Passion Fruit Waste, Journal of Hazardous Materials, 150 (2008), pp.703-712.

[17] Low, L.W., Teng, T.T., Rafatullah, M., Morad, N., Azahari, B., Adsorption Studies of Methylene Blue and Malachite Green from Aqueous Solutions by Pretreated Lignocellulosic Materials, Separation Science and Technology, 48 (2013), pp.1688-1698.

[18] Bhattacharyya, K.G., Sharma, A., Kinetics and Thermodynamics of Methylene Blue Adsorption on Neem (Azadirachta Indica) Leaf Powder, Dyes and Pigments, 65 (2005), pp.51-59.

[19] Ncibi, M.C., Mahjoub, B., Seffen, M., Kinetic and Equilibrium Studies of Methylene Blue Biosorption by Posidonia Oceanica (L.) Fibres, Journal of Hazardous Materials, 139 (2007), pp.280-285. 
[20] Vadivelan, V., Kumar, K.V., Equilibrium, Kinetics, Mechanism, and Process Design for the Sorption of Methylene Blue onto Rice Husk, Journal of Colloid and Interface Science, 286 (2005), pp.90-100.

[21] Bulut, Y., Aydın, H., A Kinetics and Thermodynamics Study of Methylene Blue Adsorption on Wheat Shells, Desalination, 194 (2006), pp.259-267.

[22] Hameed, B., Ahmad, A., Batch Adsorption of Methylene Blue from Aqueous Solution by Garlic Peel, an Agricultural Waste Biomass, Journal of Hazardous Materials, 164 (2009), pp.870-875.

[23] Oliveira, L.S., Franca, A.S., Alves, T.M., Rocha, S.D., Evaluation of Untreated Coffee Husks as Potential Biosorbents for Treatment of Dye Contaminated Waters, Journal of Hazardous Materials, 155 (2008), pp.507512.

[24] Hameed, B., Evaluation of Papaya Seeds as a Novel Non-Conventional Low-Cost Adsorbent for Removal of Methylene Blue, Journal of Hazardous Materials, 162 (2009), pp.939-944.

[25] Royer, B., Cardoso, N.F., Lima, E.C., Vaghetti, J.C., Simon, N.M., Calvete, T., Veses, R.C., Applications of Brazilian Pine-Fruit Shell in Natural and Carbonized Forms as Adsorbents to Removal of Methylene Blue from Aqueous Solutions-Kinetic And Equilibrium Study, Journal Of Hazardous Materials, 164 (2009), pp.1213-1222. [26] Ceyhan, A.A., Baytar, O., Güngör, A., Saygınl, E., Söylemez, C., Removal of Malachite Green from Aqueous Solutions using Formaldehyde Treated Elaegnus Angustifalia Seeds, Selcuk University Journal of Engineering, Science and Technology, (2013).

[27] Saka, C., Sahin, Ö., Removal of Methylene Blue from Aqueous Solutions by using Cold Plasma- and Formaldehyde- Treated Onion Skins, Coloration Technology, 127 (2011), pp.246-255.

[28] Saka, C., Şahin, Ö., Adsoy, H., Akyel, Ş.M., Removal of Methylene Blue from Aqueous Solutions by Using Cold Plasma, Microwave Radiation and Formaldehyde Treated Acorn Shell, Separation Science and Technology, 47 (2012), pp.1542-1551.

[29] Amini, M., Abbaspour, K.C., Johnson, C.A., A Comparison of Different Rule-Based Statistical Models for Modeling Geogenic Groundwater Contamination, Environmental Modelling \& Software, 25 (2010), pp.16501657.

[30] Bashir, M.J., Aziz, H.A., Yusoff, M.S., Adlan, M.N., Application of Response Surface Methodology (RSM) for Optimization of Ammoniacal Nitrogen Removal From Semi-Aerobic Landfill Leachate Using Ion Exchange Resin, Desalination, 254 (2010), pp.154-161.

[31] Geyikçi, F., Kılıç, E., Çoruh, S., Elevli, S., Modelling of Lead Adsorption from Industrial Sludge Leachate on Red Mud by Using RSM And ANN, Chemical Engineering Journal, 183 (2012), pp.53-59.

[32] Hamzaoui, A.H., Jamoussi, B., M'nif, A., Lithium Recovery from Highly Concentrated Solutions: Response Surface Methodology (RSM) Process Parameters Optimization, Hydrometallurgy, 90 (2008), pp.1-7.

[33] Kalavathy, H., Regupathi, I., Pillai, M.G., Miranda, L.R., Modelling, Analysis and Optimization of Adsorption Parameters for H3PO4 Activated Rubber Wood Sawdust Using Response Surface Methodology (RSM), Colloids and Surfaces B: Biointerfaces, 70 (2009), pp.35-45.

[34] Ghelich, R., Jahannama, M.R., Abdizadeh, H., Torknik, F.S., Vaezi, M.R., Central Composite Design (CCD)Response Surface Methodology (RSM) of Effective Electrospinning Parameters on PVP-B-Hf Hybrid Nanofibrous Composites for Synthesis of Hfb2-Based Composite Nanofibers, Composites Part B: Engineering, 166 (2019), pp.527-541.

[35] Erbay, Z., Icier, F., Optimization of Hot Air Drying of Olive Leaves Using Response Surface Methodology, Journal of Food Engineering, 91 (2009), pp.533-541.

[36] Rai, A., Mohanty, B., Bhargava, R., Supercritical Extraction of Sunflower Oil: A Central Composite Design for Extraction Variables, Food Chemistry, 192 (2016), pp.647-659.

[37] Pimenta, C.D., Silva, M.B., de Morais Campos, R.L., de Campos Junior, W.R., Desirability and Design of Experiments Applied to the Optimization of the Reduction of Decarburization of the Process Heat Treatment for Steel Wire SAE 51B35, American Journal of Theoretical and Applied Statistics, 7 (2018), pp.35-44.

[38] Vargas, A.M.M., Cazetta, A.L., Kunita, M., Silva, T.L., Almeida, V., Adsorption of Methylene Blue on Activated Carbon Produced from Flamboyant Pods ( Delonix Regia): Study of Adsorption Isotherms and Kinetic Models, Chemical Engineering Journal, 168 (2011), pp.722-730.

[39] Sari, A., Tuzen, M., Citak, D., Soylak, M., Equilibrium, Kinetic and Thermodynamic Studies of Adsorption of $\mathrm{Pb}$ (II) from Aqueous Solution onto Turkish Kaolinite Clay, Journal of Hazardous Materials, 149 (2007), pp.283-291.

[40] Dursun, A.Y., Kalayci, Ç.S., Equilibrium, Kinetic and Thermodynamic Studies on the Adsorption of Phenol onto Chitin, Journal of Hazardous Materials, 123 (2005), pp.151-157.

[41] KUTLUAY, S., Benzen Uçucu Organik Bileşiğinin Badem Kabuğundan Üretilen Char Üzerine Gaz Fazı Adsorpsiyonu: Kinetik, Denge ve Termodinamik, Bitlis Eren Üniversitesi Fen Bilimleri Dergisi, 8 (2019), pp.1432-1445. 